\title{
Expression of bone morphogenetic protein-2 and -7 in urinary bladder cancer predicts time to tumor recurrence
}

Bolesław Kuzaka ${ }^{1}$, Marek Janiak², Krzysztof H. Włodarski' ${ }^{2}$, Piotr Radziszewski ${ }^{1}$, Paweł K. Włodarski

\author{
${ }^{1}$ Department of General, Oncologic and Functional Urology, Medical University \\ of Warsaw, Warsaw, Poland \\ 2Department of Histology and Embryology, Medical University of Warsaw, Warsaw, \\ Poland
}

Submitted: 8 April 2013

Accepted: 19 August 2013

Arch Med Sci 2015; 11, 2: 378-384

DOI: 10.5114 /aoms.2014.46796

Copyright @ 2015 Termedia \& Banach

\section{Abstract}

Introduction: Urinary bladder cancer patients who have undergone transurethral resection of bladder tumor (TURBT) are at risk of recurrence. This study aims to correlate the level of bone morphogenetic protein (BMP) expression with urothelial carcinoma invasiveness, TNM stage and time to recurrence after TURBT.

Material and methods: In 33 specimens of healthy transitional epithelium and 42 of urothelial carcinoma, BMP2, BMP4 and BMP7 expression was determined by real-time polymerase chain reaction. Patients who underwent TURBT were followed up for 1 year.

Results: BMP2 and BMP7 were downregulated in infiltrating urothelial carcinoma, the relative expression being $0.76(p=0.04)$ and $0.28(p=0.025)$ respectively, while BMP4 was downregulated in non-invasive tumors. High expression of BMP2 and BMP7 correlated with prolonged time to recurrence (log-rank: $p=0.01$ and $p=0.03$ respectively).

Conclusions: Low expression of BMP2 and BMP7 is associated with shorter time to recurrence. The BMP expression levels are not indicative of tumor stage.

Key words: bone morphogenetic protein 2, bone morphogenetic protein 4 , bone morphogenetic protein 7 , urothelial carcinoma, urinary tract epithelium.

\section{Introduction}

Bone morphogenetic proteins (BMPs) are pleiotropic growth factors that were originally isolated from bone matrix and are involved in inducing cartilage and bone formation [1-3]. Apart from bone formation, they are also involved in the regulation of several key steps of cell differentiation during embryonic development. Bone morphogenetic proteins are members of the transforming growth factor $\beta$ (TGF- $\beta$ ) superfamily that are ligands for the SMAD receptor class. The signaling cascade mediated by SMADs is regulated by multiple factors termed BMP inhibitors, such as noggin, chordin, follistatin and gremlin protein, which inhibit BMP activity through ligand sequestering [4-7] or by dorsomorphin, which acts as a specific inhibitor of the BMP receptor [8]. Besides their critical function in mammalian development, BMPs are engaged in oncogenesis [9]. The mechanism of action of BMPs relies chiefly on their ability to activate invasive pathways via PI3K/AKT or MAPK [10] or by the induction of proliferation [11]. Urothelial carcinoma (UC) cells

\author{
Corresponding author: \\ Paweł Włodarski MD, PhD \\ Department of Histology \\ and Embryology \\ Center for Biostructure \\ Research \\ Medical University of Warsaw \\ 5 Chalubinskiego St \\ 02-004 Warsaw, Poland \\ Phone/fax: +48 226295282 \\ E-mail: pawel.wlodarski@ \\ wum.edu.pl
}


frequently lose expression of the BMP receptor, which, in consequence, increases production of BMPs by these cells. Secreted BMPs enhance tumor growth in a paracrine manner [12].

Although the overall mortality associated with urinary bladder cancer is currently decreasing, this disease is still a major therapeutic challenge [13]. Urinary bladder cancer affected over 350,000 individuals worldwide and was the cause of 145,000 deaths in 2002 [14]. The 5-year relative survival depends on tumor stage and localization and is $81.7 \%, 66 \%$ and $70.6 \%$ when the tumor is located within the bladder, renal pelvis and ureter, respectively [15]. In Poland, according to a recent National Cancer Registry report (2010), urinary bladder cancer is the third and the thirteenth most frequently diagnosed male and female cancer, with the annual number of new cases being 4919 and 1377 , respectively. The disease is also the sixth male (2470 deaths) and the fifteenth female (641 deaths) deadliest cancer in Poland [16]. Phenotypic features such as tumor grade, stage and involved lymph nodes are factors that affect survival after radical cystectomy, but their assessment is problematic and time consuming [17]. Therefore, new prognostic factors are sought to increase treatment efficiency by providing alternative treatment modalities for individuals with high or low risk of disease recurrence. Such "tailored" therapy would improve high-risk patients' survival while low-risk patients would not be burdened by unnecessary medical procedures.

Preliminary data have implicated BMP2 and BMP4 as factors that are involved in the development of urothelial carcinoma [18-20]. Recently, it has been shown that BMP2 expression level correlates with bone metastasis in urothelial bladder cancer [21]. Although there are no reports on BMP7 participation in UC progression to date, it has been shown to be involved in other cancers, and the expression of BMPs has been demonstrated to have a prognostic value in certain neoplastic malignancies [22-24]. We hypothesized, therefore, that their expression may also be a prognostic biomarker in urothelial carcinoma. Consequently, in this study we evaluated the expression of BMP2, BMP4 and BMP7 in human normal urothelium and in urothelial carcinoma at various stages of tumor development to characterize the relationship between BMP expression and tumor progression, invasiveness and the time to relapse.

\section{Material and methods}

\section{Patients and samples}

The study was approved by the Medical University of Warsaw Ethics Committee, and written informed consent was obtained from all participating patients. One hundred and forty-one patients of the Department of General, Oncologic and Functional Urology of the Medical University of Warsaw who underwent surgical treatment for urothelial carcinoma were recruited to the study. Fragments of transformed epithelium of UC and of healthy transitional epithelium (TE) of the urinary tract, that were excised for medical reasons, were used for the assessment of BMP expression. Epithelial tissue was recovered from solid tumor masses with no underlying muscularis. Tissue was then immersed in RNAlater RNA Stabilization Reagent (Ambion), incubated at $4^{\circ} \mathrm{C}$ overnight and then stored at $-20^{\circ} \mathrm{C}$ until processing. Only samples that yielded good quality RNA were used for gene expression. The investigators were blinded to the origin of the RNA that was subjected to quality control. A total of 33 TE and 42 UC histologically confirmed specimens were examined. Tumors were staged according to the WHO TNM classification [25]. Table I summarizes the characteristics of the tissue samples, the histopathological evaluation of tumor grades and the TNM stage.

Table I. Summary of tissue sample used in the study. Donor sex: $\mathrm{M}$ - male; F - female. In some samples grade data were missing

\begin{tabular}{|c|c|c|}
\hline Parameter & $\begin{array}{l}\text { Healthy } \\
\text { urothelium }\end{array}$ & $\begin{array}{l}\text { Urothelial } \\
\text { carcinoma }\end{array}$ \\
\hline \multicolumn{3}{|l|}{ Patients: } \\
\hline Number (M/F) & $33(14 / 19)$ & $42(30 / 12)$ \\
\hline $\begin{array}{l}\text { Age, mean (range) } \\
\text { [years] }\end{array}$ & $63.4(26-88)$ & $73.1(49-91)$ \\
\hline \multicolumn{3}{|l|}{ Tissue origin: } \\
\hline Renal pelvis & 6 & 4 \\
\hline Urinary bladder & 8 & 37 \\
\hline Ureter & 19 & 1 \\
\hline \multicolumn{3}{|l|}{ Grade: } \\
\hline G1 & - & 5 \\
\hline G2 & - & 27 \\
\hline G3 & - & 8 \\
\hline \multicolumn{3}{|l|}{ TNM: } \\
\hline pTa & - & 24 \\
\hline pT1 & - & 5 \\
\hline pT2 & - & 3 \\
\hline рT3 & - & 4 \\
\hline pT4 & - & 6 \\
\hline
\end{tabular}




\section{RNA isolation and CDNA synthesis}

Total RNA was isolated using TriPure Isolation Reagent (Roche), according to the manufacturer's instructions. Reverse transcription was performed using Transcriptor First Strand cDNA Synthesis Kit (Roche) with anchored-oligo(dT) ${ }_{18}$ primers according to the manufacturer's protocol. The cDNA template was diluted 10 -fold for analysis by real-time PCR.

\section{Real-time polymerase chain reaction}

Quantitative real-time polymerase chain reactions (RT-PCR) were performed in a 7500 Real Time PCR system (Applied Biosystems). TaqManGene Expression Assays (BMP2 - Hs00154192_m1, BMP4 -Hs00370078_m1, BMP7 - Hs00233476_m1, TBP -4333769F) and master mix were purchased from Applied Biosystems. Each reaction was carried out in a volume of $20 \mu \mathrm{l}$. All samples were tested in duplicate. Non-template control samples were included in each PCR run. BMP gene expression was normalized to expression of TATA box binding protein (TBP) [26]. Samples were considered negative for the expression of a given mRNA when $\mathrm{Ct}$ exceeded 35 .

\section{Statistical analysis}

Relative gene expression was assessed by the comparative CT method (ddCT), using DataAssist Software (Applied Biosystems) and Excel (Microsoft). Normalized expression of BMPs in UC was compared to their expression in normal TE; thus the expression of BMPs in TE was always considered as a reference unit valued 1 . Statistica software version 9.0 (StatSoft, Tulsa, OK) was used for statistical analysis.

The Mann-Whitney $U$ test was employed to compare gene expression among samples. A $p$ value $<0.05$ was considered statistically significant. Samples with TNM stage pT1 and higher were classified as invasive urothelial carcinoma. Spearman's rank correlation coefficient test was performed for the correlation of BMP expression with TNM stages. Time to recurrence was defined as time from surgical removal of UC to the next surgical intervention caused by relapse of UC or cancer confirmation in cystoscopy. The data obtained were analyzed by the Kaplan-Meier method (StatSoft, Tulsa, OK) and log-rank test (MedCalc).

\section{Results}

The analysis of BMP expression in normal TE and cancerous UT (regardless of its grade or stage) revealed that BMP2 and BMP7 were expressed at a similar level in UC and TE ( $p=0.7$ and $p=0.94$, respectively), while the expression of BMP4 was significantly lower in UC, $p=0.001$ (Figure $1 \mathrm{~A}$ ).
There was no differences in BMP expression levels in bladder and upper tract samples. The expression of BMPs in cancer samples was then analyzed according to the invasiveness of the tumor determined by histopathological examination (Figures $1 \mathrm{~B}-\mathrm{D})$. This investigation revealed that, in comparison to normal TE, BMP2 was modestly but significantly downregulated in the advanced, invasive stage of the urothelial carcinoma $(p=0.04)$ (Figure 1 B). Similarly, BMP4 was significantly downregulated in non-infiltrating UC $(p=0.0002)$ although in more advanced tumors its expression was comparable to the level present in the normal TE ( $p=0.13)$ (Figure $1 \mathrm{C})$. Quite the opposite modulation was observed in BMP7 expression. This gene was insignificantly upregulated in the non-invasive stage of disease $(p=0.12)$, whereas in the invasive UC its expression was significantly downregulated $(p=0.025)$ (Figure $1 \mathrm{D})$. These results demonstrate that the expression of BMPs 2 , 4 and 7 varies in UC progression, but the pattern of these changes is different for each of the analyzed genes.

To determine whether BMP expression status is related to the tumor stage, we analyzed the expression levels of studied genes in various TNM stages (Figure 2). To assess this relationship, we classified each UC sample into one of 3 groups, pTa, pT1-2 and pT3-4, according to TNM staging [23], and analyzed the BMP status. PT1 and PT2 TNM stages were combined for the analysis, because both are associated with limited invasion, in contrast to the noninvasive stage pTa. No correlation was found between expression of BMP2 or BMP4 and TNM stages (Figures $2 \mathrm{~A}, \mathrm{~B}$ ), although both of these genes showed a different expression pattern in comparison to normal TE (Figures $1 \mathrm{~B}, \mathrm{C}$ ). In contrast, BMP7 expression was found to be closely related to disease stage. BMP7 was upregulated in the early (pTa) stage and significantly reduced in the more advanced stages, thus achieving a negative correlation with the TNM scale $(r=-0.42 ; p=0.005)$ (Figure $2 \mathrm{C})$.

Lastly, we made an effort to determine whether BMP expression in the transitional epithelium of the resected tumor is correlated with the time to relapse of the tumor. To do this, we followed up the cohort of 24 urinary bladder cancer patients who underwent TURBT. BMP expression was determined in the transitional epithelium resected during the initial operation. Patients were followed up for 12 months from this date (Figure 3). The median time to recurrence for all cases was 262 days (Figure $3 \mathrm{~A}$ ). For analysis, patients were divided according to expression of BMP2, BMP4 and BMP7 into individuals in whom the tumor had low (first tertile, dotted line in the figure) or medium-high (second and third tertile, solid line 
A

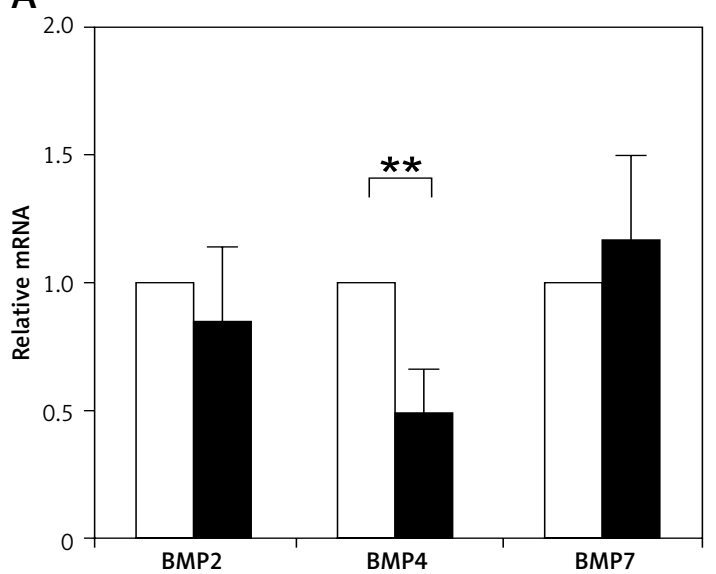

C

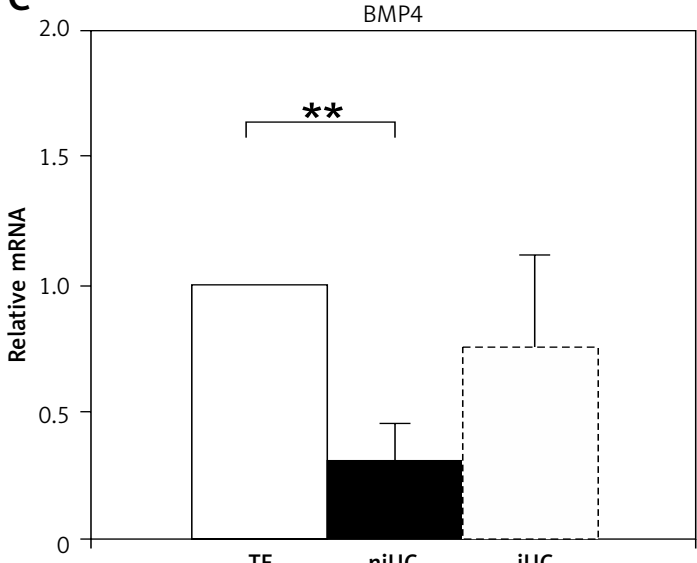

B

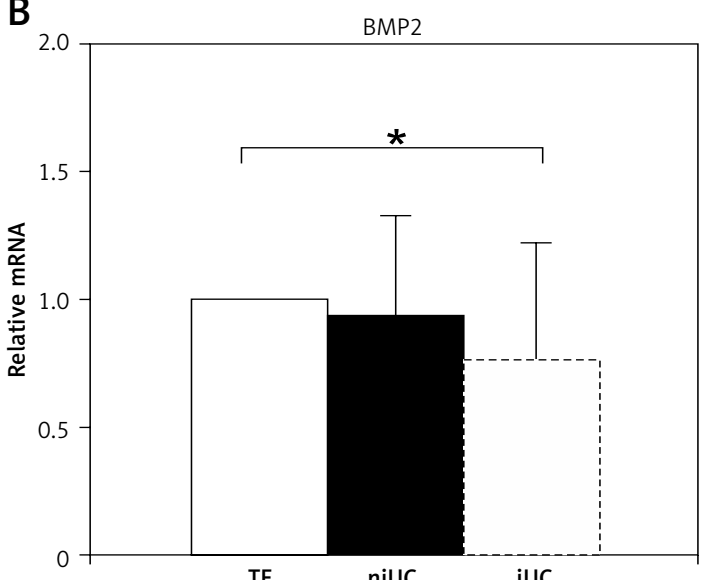

D

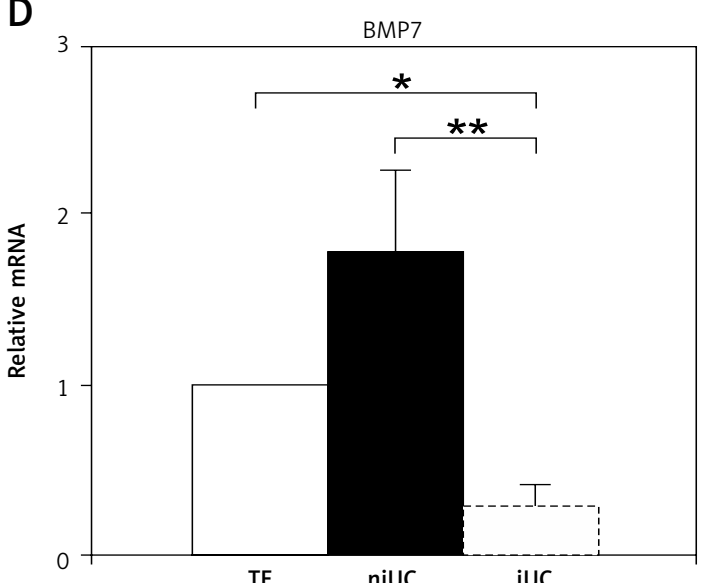

Figure 1. The BMP2, BMP4 and BMP7 expression level relative to healthy transitional epithelium (TE). Comparison between healthy urothelial transitional tissue $(n=33$, empty bars) and urothelial carcinoma samples $(n=42$, black bars) (A), BMP2 (B), BMP4 (C) and BMP7 (D) relative expression level in healthy TE $(n=33$, TE), non-invasive urothelial carcinoma ( $n=24$, niUC) and invasive urothelial carcinoma $(n=18$, iUC)

Significance of the difference is indicated as follows ${ }^{*} p<0.05$; ${ }^{* *} p<0.01$; Error bars represent SEM.

in the figure) gene expression level. As presented in Figure 3 C, BMP4 expression did not correlate with time to recurrence of urothelial carcinoma $(p=0.4)$, whereas the low expression of BMP2 and BMP7 was significantly correlated with a shorter time to tumor relapse $(p=0.01$ and $p=0.03$ respectively) (Figures 3 B, D).

\section{Discussion}

Prognostic factors are highly demanded in today's medicine, including relatively well-managed diseases, such as urothelial carcinoma. In this study, we tested three candidates for biomarkers of urinary bladder carcinoma progression - BMP2, BMP4 and BMP7 - that have previously been shown to be modulated in the course of other cancers although still little is known about their role in the pathogenesis of urinary bladder cancer. To date, the only indication of their involvement in this cancer's pathology was a report on BMP2 in metastasis $[19,21]$. Our preliminary analysis of 42 urothelial carcinoma samples and 33 tran- sitional epithelium samples revealed that expression of BMP2 and 7 is similar in healthy and transformed transitional epithelium. Only BMP4 was significantly downregulated in UC samples. These results, however, did not consider grade or stage of the tumor. In an attempt to find out whether BMPs 2, 4 and 7 modulated the progression of the disease, urinary carcinoma samples were divided into groups of similar stage, and BMP expression was assessed in these groups. We found that BMP2 has an almost stable expression in tumor tissues in all stages of disease progression (Figures $1 \mathrm{~A}, \mathrm{~B}, 2 \mathrm{~A}$ ); hence this protein was not modulated in a way that would directly indicate its involvement in UC development. The expression of the other two BMPs analyzed in our study - BMP4 and BMP7 - significantly varied depending on the stage of urothelial carcinoma development. Generally, in comparison to normal TE, the expression of BMP4 was lowered in UC, especially at its early, non-invasive stage (Figure $1 \mathrm{C}$ ). These results were consistent with those obtained by Zaravinos et al. 
A

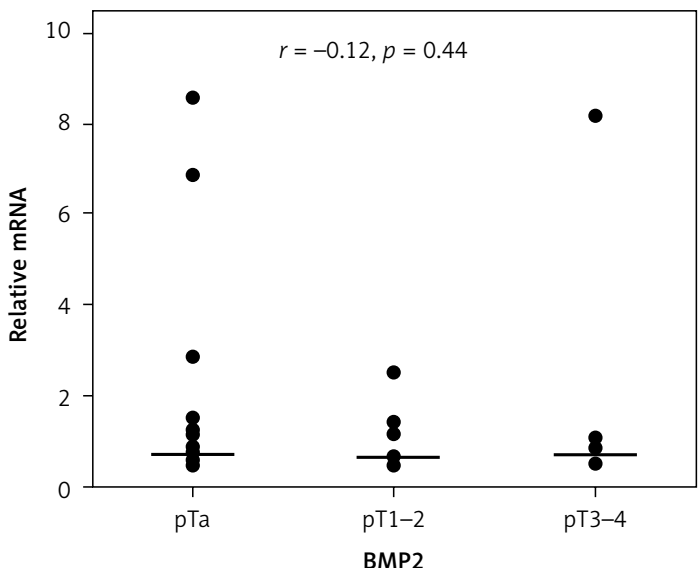

C

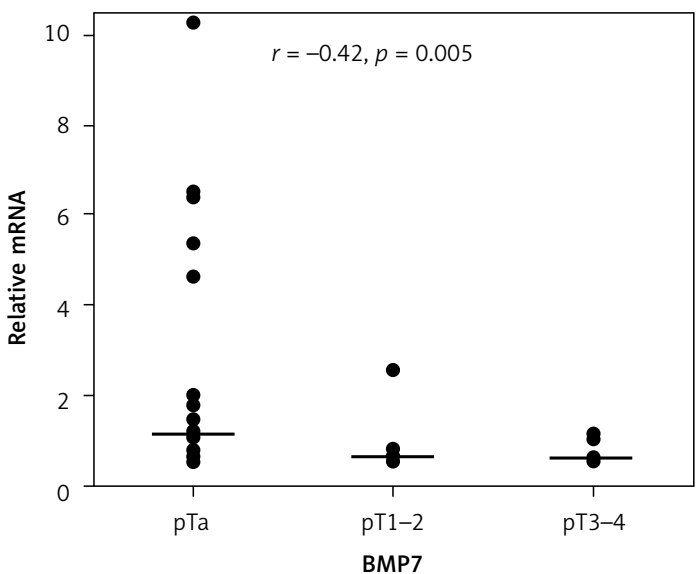

[20], who reported lowered expression of BMP4 in bladder cancer. The level of BMP4 was not correlated with TNM stages of urothelial carcinoma (Figure 2 B). Analysis of other reports suggests that the relationship between cancer progression and BMP4 expression is disease dependent. In atypical teratoid/rhabdoid tumors, high BMP4 expression was negatively associated with patients' survival [23]. In contrast to this, in gastric adenocarcinoma, BMP4 expression is inversely related to tumor invasiveness and presence of lymph node metastasis [27]. BMP4 was shown to downregulate proliferation and promote cell differentiation in both glioma [28] and medulloblastoma cell lines [29]. In advanced ovarian cancer, high expression of BMP4 was associated with better progression-free and overall survival [30].

The expression of BMP7 in urothelial carcinoma was grade- and stage-dependent. In the early, non-invasive stage, the level of BMP7 was elevated, but in the more advanced and invasive phase of the tumor growth, BMP7 expression had dropped significantly (Figure $1 \mathrm{D}$ ). Similarly, in the advanced TNM stages of UC, the level of BMP7 was lowered when compared to the less advanced stages of urothelial carcinoma and to TE. The correlation of
B

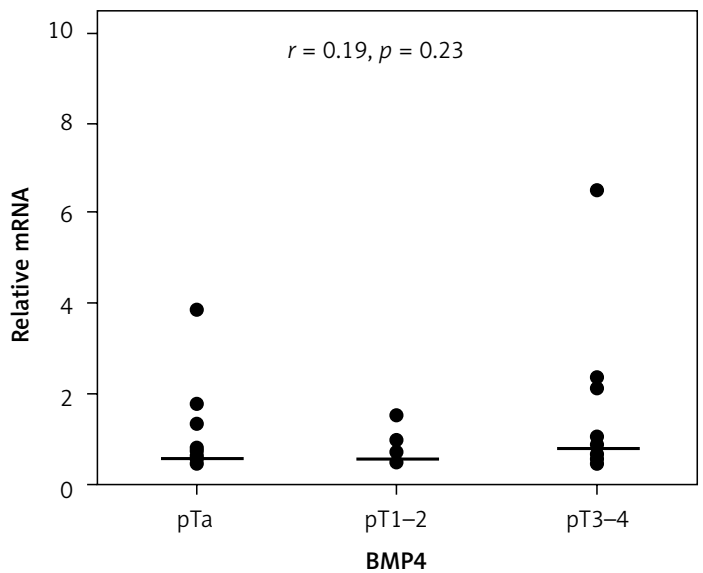

Figure 2. BMP2 (A), BMP4 (B), BMP7 (C) expression at different TNM stages (pTa $(n=24)$, pT1-2 $(n=8)$, pT3-4 $(n=10)$ ). Presented values are relative to mean of normal transitional epithelium

Horizontal lines represent median. $r$ - Spearman's rank correlation coefficient between gene expression and TNM stages; $p$ - statistical significance.

BMP7 expression with higher TNM stages in UC was significant $(r=-0.42 ; p=0.005)$; therefore we postulate that this molecule is a good candidate to monitor tumor progression at the molecular level. The principal result of the study comes from the one-year follow-up of 24 patients who underwent TURBT. In these patients BMP expression in the resected urothelial carcinoma was correlated with the time to recurrence during 12 months of observation. In a log-rank test we found no correlation between BMP4 expression and time to urothelial carcinoma relapse (Figure $3 \mathrm{C}$ ). In contrast, patients with tumors with low expression of BMP2 or BMP7 had a shorter time to UC relapse in comparison to patients with medium/high expression of these genes (Figures $3 \mathrm{~B}, \mathrm{D}$ ). This indicates BMP2 and BMP7 as potential biomarkers that could have predictive value in the course of UC. The observation regarding the prognostic value of BMP2 is in concert with the results of Ma et al. [31], who found that low BMP2 expression in ovarian cancer was associated with a poor prognosis. Interestingly, in contrast to these findings, high expression of BMP2 was associated with worse prognosis in gastric cancer [22] and glioma [32]. These opposite effects of BMP2 on disease recurrence indicate that 
A

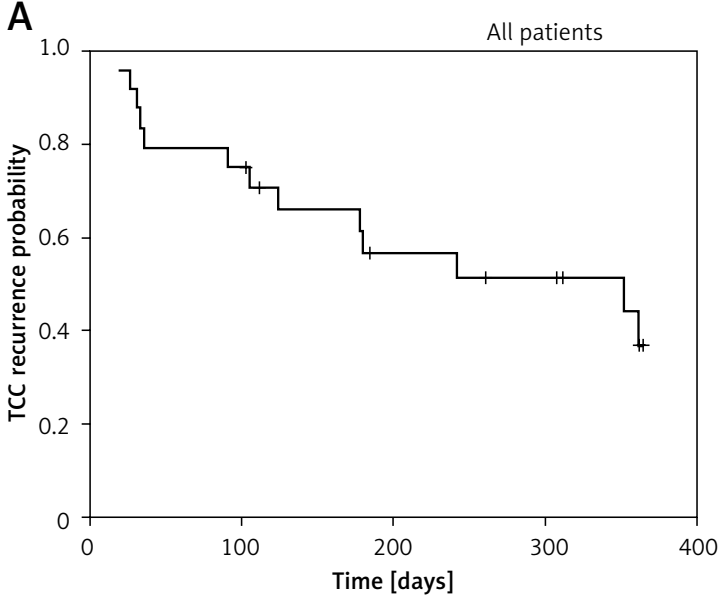

C

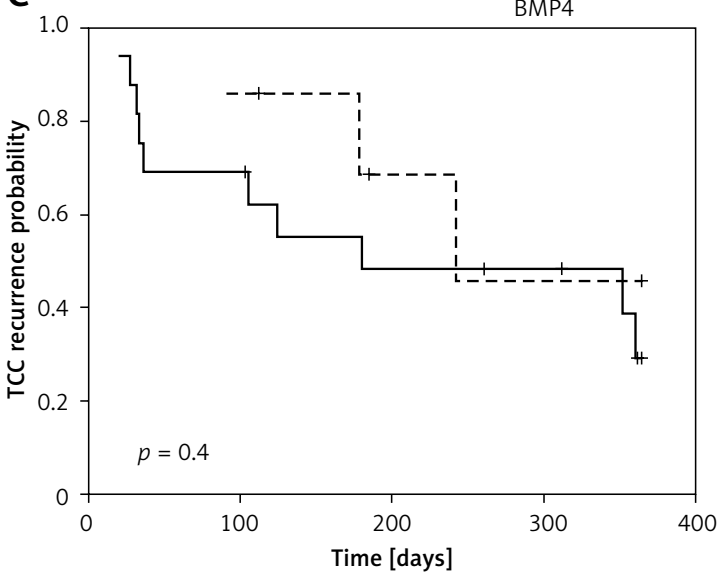

B

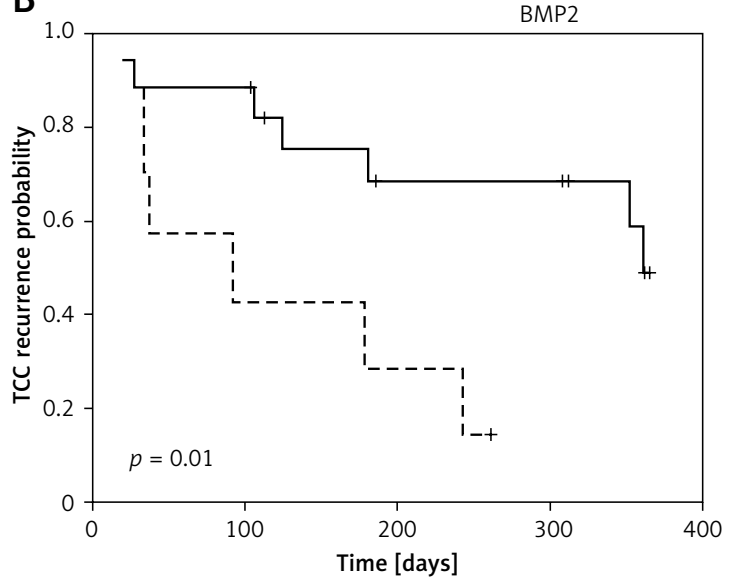

D

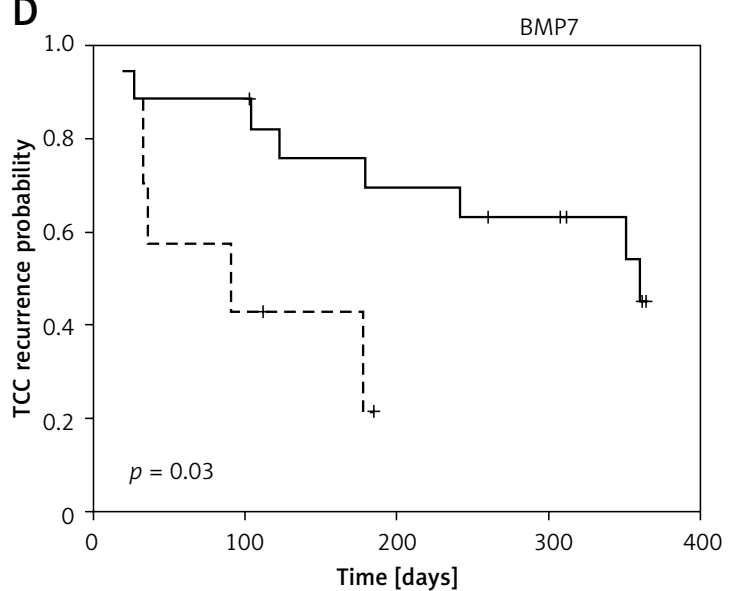

Figure 3. Kaplan-Meier estimators for UC recurrence probability for all analyzed subjects $(n=24)($ A), BMP2 (B), BMP4 (C), BMP7 (D) Kaplan-Meier estimators for UC recurrence probability respectively

Dashed line - low BMP expression, solid line - medium/high BMP expression. Significance of the differences is indicated (logrank test). +Censored data.

the clinically relevant correlation between patients' outcome and BMP2 level is disease-dependent. Our findings on BMP7 as a potential prognostic factor in urothelial carcinoma are similar to those observed in renal cell carcinoma, where BMP7 expression was down-regulated in cancer tissue and a high BMP7 level was a favorable prognostic factor of disease-free and overall survival [24]. Similar to BMP2 and BMP4, the relationship between cancer progression and BMP7 depends on the type of the tumor. In breast cancer, BMP7 expression level not only varies between tumor subtypes (lobular carcinomas and ductal carcinoma) but its expression was associated with accelerated bone metastasis [33]. A similar association between BMP7 and poor prognosis or higher aggressiveness of the tumor was observed in colorectal [34] and gastric [35] cancers. Although our observations are limited by the small number of participating patients and need to be validated in broader studies, the data presented here suggest that BMP2 and BMP7 are promising candidates for biomarkers useful for evaluation of recurrence risk in urothelial carcinoma.
In conclusion, BMP2, BMP4 and BMP7 expression in UC tumor fluctuate in progression of this cancer. Low levels of BMP2 and BMP7 in tumor tissue were associated with shorter time to relapse, and hence can be considered as prognostic factors in UC.

\section{Acknowledgments}

Bolesław Kuzaka and Marek Janiak contributed equally to this work.

This work was supported by grant $1 M 7 / R R W / D$ from the Medical University of Warsaw. The authors are grateful to Dr. Robert Crayton for critical reading and helpful suggestions concerning this manuscript.

\section{Conflict of interest}

The authors declare no conflict of interest.

\section{References}

1. Hogan BL. Bone morphogenetic proteins: multifunctional regulators of vertebrate development. Genes Dev 1996; 10: 1580-94. 
2. Wozney JM, Rosen V, Celeste AJ, et al. Novel regulators of bone formation: molecular clones and activities. Science 1988; 242: 1528-34.

3. Urist MR, O'Connor BT, Burwell RG. Bone grafts, derivatives and substitutes. Butterworth-Heinemann, Oxford 1994.

4. Feeley BT, Krenek L, Liu N, et al. Overexpression of noggin inhibits BMP-mediated growth of osteolytic prostate cancer lesions. Bone 2006; 38: 154-66.

5. Pathi S, Rutenberg JB, Johnson RL, Vortkamp A. Interaction of Ihh and BMP/Noggin signaling during cartilage differentiation. Dev Biol 1999; 209: 239-53.

6. Fainsod A, Deissler K, Yelin R, et al. The dorsalizing and neural inducing gene follistatin is an antagonist of BMP-4. Mech Dev 1997; 63: 39-50.

7. Pereira RC, Economides AN, Canalis E. Bone morphogenetic proteins induce gremlin, a protein that limits their activity in osteoblasts. Endocrinology 2000; 141: 4558-63.

8. Yu PB, Deng DY, Lai CS, et al. BMP type I receptor inhibition reduces heterotopic ossification. Nat Med 2008; 14: 1363-9.

9. Yan H, Zhu S, Song C, Liu N, Kang J. Bone morphogenetic protein (BMP) signaling regulates mitotic checkpoint protein levels in human breast cancer cells. Cell Signal 2012; 24: 961-8.

10. Kang $\mathrm{MH}$, Oh SC, Lee $\mathrm{HJ}$, et al. Metastatic function of BMP-2 in gastric cancer cells: the role of PI3K/AKT, MAPK, the NF-kappaB pathway, and MMP-9 expression. Exp Cell Res 2011; 317: 1746-62.

11. Kallioniemi A. Bone morphogenetic protein 4-a fascinating regulator of cancer cell behavior. Cancer Genet 2012; 205: 267-77.

12. Kim IY, Kim SJ. Role of bone morphogenetic proteins in transitional cell carcinoma cells. Cancer Lett 2006; 241: 118-23.

13. Ferlay J, Randi G, Bosetti C, et al. Declining mortality from bladder cancer in Europe. BJU Int 2008; 101: 11-9.

14. Kakehi Y, Hirao Y, Kim WJ, et al. Bladder Cancer Working Group report. Jpn J Clin Oncol 2010; 40 Suppl. 1: i57-64.

15. David KA, Mallin K, Milowsky MI, Ritchey J, Carroll PR, Nanus DM. Surveillance of urothelial carcinoma: stage and grade migration, 1993-2005 and survival trends, 1993-2000. Cancer 2009; 115: 1435-47.

16. Wojciechowska U, Didkowska J, Zatoński W. Cancer incidence - tables and figures. In: Cancer in Poland in 2010. Wojciechowska U, Didkowska J, Zatoński W (eds.). Polish National Cancer Registry. Department of Epidemiology and Cancer Prevention Warsaw 2012; 43-80.

17. Aglamis E, Toktas G, Unluer E, Tasdemir C, Ceylan C. Prognostic factors in radical cystectomy affecting survival. Arch Med Sci 2012; 8: 650-4.

18. Hung TT, Wang H, Kingsley EA, Risbridger GP, Russell PJ. Molecular profiling of bladder cancer: involvement of the TGF-beta pathway in bladder cancer progression. Cancer Lett 2008; 265: 27-38.

19. Komai Y, Morimoto S, Saito K, Urushibara M, Sakai K, Ikeda S. Possible involvement of bone morphogenetic protein 2 in heterotopic ossification in metastatic lesion from urothelial carcinoma of bladder. Int J Urol 2006; 13: $1126-8$.

20. Zaravinos A, Lambrou GI, Boulalas I, Delakas D, Spandidos DA. Identification of common differentially expressed genes in urinary bladder cancer. PLoS One 2011; 6: e18135.

21. Yang ZJ, Liu FX, Yang YS, Yang X, Zhu GX. Expression of bone-morphogenetic protein 2 and tumor necrosis factor alpha correlates with bone metastases in bladder urothelial carcinoma. Ann Diagn Pathol 2013; 17: 51-3.

22. Park Y, Kang MH, Seo HY, et al. Bone morphogenetic protein-2 levels are elevated in the patients with gastric cancer and correlate with disease progression. Med Oncol 2010; 27: 1192-9.

23. Birks DK, Donson AM, Patel PR, et al. High expression of BMP pathway genes distinguishes a subset of atypical teratoid/rhabdoid tumors associated with shorter survival. Neuro Oncol 2011; 13: 1296-307.

24. Basic-Jukic N, Hudolin T, Radic-Antolic M, et al. Bone morphogenetic protein-7 expression is down-regulated in human clear cell renal carcinoma. J Nephrol 2011; 24: 91-7.

25. Sobin LH, Gospodarowicz M, Wittekind C (eds.). TNM classsification of malignant tumors. UICC Interanational Union Against Cancer. 7th ed. Wiley-Blackwell 2009; 262-5.

26. Ohl F, Jung M, Radonić A, Sachs M, Loening SA, Jung K. Identification and validation of suitable endogenous reference genes for gene expression studies of human bladder cancer. J Urol 2006; 175: 1915-20.

27. Kim SG, Park HR, Min SK, et al. Expression of bone morphogenic protein-4 is inversely related to prevalence of lymph node metastasis in gastric adenocarcinoma. Surg Today 2011; 41: 688-92.

28. Liu B, Tian D, Yi W, et al. Effect of bone morphogenetic protein 4 in the human brain glioma cell line U251. Cell Biochem Biophys 2010; 58: 91-6.

29. Zhao H, Ayrault O, Zindy F, Kim JH, Roussel MF. Post-transcriptional down-regulation of Atoh1/Math1 by bone morphogenic proteins suppresses medulloblastoma development. Genes Dev 2008; 22: 722-7.

30. Laatio L, Myllynen P, Serpi R, et al. BMP-4 expression has prognostic significance in advanced serous ovarian carcinoma and is affected by cisplatin in OVCAR-3 cells. Tumour Biol 2011; 32: 985-95.

31. Ma Y, Ma L, Guo Q, Zhang S. Expression of bone morphogenetic protein-2 and its receptors in epithelial ovarian cancer and their influence on the prognosis of ovarian cancer patients. J Exp Clin Cancer Res 2010; 29: 85.

32. Liu C, Tian G, Tu Y, Fu J, Lan C, Wu N. Expression pattern and clinical prognostic relevance of bone morphogenetic protein-2 in human gliomas. Jpn J ClinOncol 2009; 39 625-31.

33. Alarmo EL, Korhonen T, Kuukasjärvi T, Huhtala H, Holli $\mathrm{K}$, Kallioniemi A. Bone morphogenetic protein 7 expres sion associates with bone metastasis in breast carcinomas. Ann Oncol 2008; 19: 308-14.

34. Motoyama K, Tanaka F, Kosaka Y, et al. Clinical significance of BMP7 in human colorectal cancer. Ann Surg Oncol 2008; 15: 1530-7.

35. Aoki M, Ishigami S, Uenosono $Y$, et al. Expression of BMP-7 in human gastric cancer and its clinical significance. Br J Cancer 2011; 104: 714-8. 